\title{
Ion Pair-Directed C-H Activation on Flexible Ammonium Salts: meta- Selective Borylation of Quaternized Phenethylamines and Phenylpropylamines
}

\author{
Madalina T. Mihai, Holly J. Davis, Georgi R. Genov, and Robert J. Phipps*(1) \\ Department of Chemistry, University of Cambridge, Lensfield Road, Cambridge, CB2 1EW, United Kingdom \\ Supporting Information
}

ABSTRACT: Ion pairing has unexplored potential as a key catalyst-substrate interaction for controlling regioselectivity and site-selectivity in transitionmetal catalysis, particularly in the area of $\mathrm{C}-\mathrm{H}$ activation. However, there is a significant perceived challenge that has meant that few have investigated this approach to date-that of the low directionality, which could present an unsurmountable challenge if seeking positional selectivity on flexible substrates. Herein, we demonstrate that even flexible substrates with several freely rotatable bonds undergo ion pair-directed $\mathrm{C}-\mathrm{H}$ borylation with good to

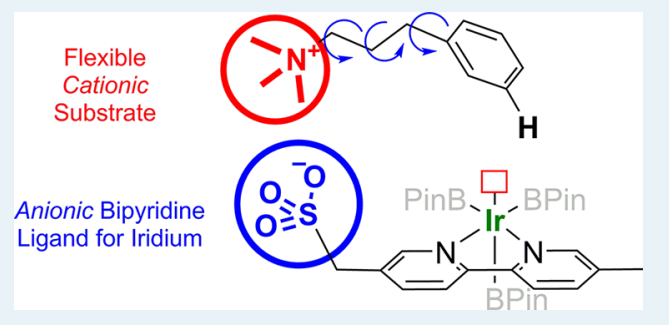
excellent levels of regiocontrol for the arene meta-position. Furthermore, we demonstrate that in specially designed competition substrates, ion pair direction prevails over competing hydrogen bond direction. We anticipate that these findings will inspire the greater incorporation of ion-pairing into site-selective catalytic strategies.

KEYWORDS: $\mathrm{C}-\mathrm{H}$ activation, borylation, ion-pairing, noncovalent interactions, regioselectivity

$\mathrm{T}$ he application of noncovalent interactions to exert control in transition-metal catalysis is a potentially very powerful strategy. ${ }^{1}$ Nature utilizes this approach extensively through the use of cofactors as the reactive center in partnership with an enzyme, which provides the necessary environment to achieve desired selectivity. ${ }^{2}$ Chemical efforts to mimic this partnership using hydrogen bonds ${ }^{3}$ and ion pairs ${ }^{4}$ have led to numerous advances in control of enantioselectivity. Compared to hydrogen bonds, ion pairs are typically perceived as lacking the directionality necessary to achieve high levels of positional control and as such have been underexplored in regioselective or site-selective reactions using transition metals. ${ }^{5-7}$ This is despite the great potential of ion pairing as a tool for directing $\mathrm{C}-\mathrm{H}$ bond functionalization-the Coulombic interaction is strong and potentially resilient to reaction conditions that may disrupt weaker hydrogen bonds. In the course of their pioneering work on steroid functionalization, Breslow and coworkers carried out several fascinating studies using stoichiometric ion paired templates to achieve remote $\mathrm{sp}^{3} \mathrm{C}-\mathrm{H}$ functionalization via a radical mechanism. ${ }^{8}$ The first concerned selective functionalization of an extended alkyl chain and in order to obtain good site-selectivity it was necessary to employ two ion-pairing interactions to reduce overall flexibility (Figure 1a). ${ }^{9}$ Subsequently, they were able to use a single ion-pairing interaction to enable radical chlorination of a rigid quaternary ammonium-functionalized steroid with encouraging siteselectivity and in a single example were able to show that catalytic turnover, albeit low, was possible via ion exchange (Figure $1 \mathrm{~b}) .{ }^{10}$ Following these innovative studies, few developments in using ion-pairing to control $\mathrm{C}-\mathrm{H}$ functionalization have occurred. We recently reported an ion pair-directed approach for controlling regioselectivity in iridium-catalyzed borylation of aromatic $\mathrm{C}-\mathrm{H}$ bonds in which an anionic ligand for iridium ion pairs with a cationic ammonium salt substrate (Figure 1c). ${ }^{11}$ In that work, two classes of aromatic quaternary ammonium salts were explored: those derived from anilines and benzylamines (Figure 1d). Both of these substrate classes possess very low conformational freedom. For the former, there is essentially none, and for the latter, there is only a single rotatable bond, which in reality is significantly restricted in its accessible conformations by the bulky quaternary ammonium functionality. Hence, these rigid substrates constituted an ideal starting point for establishing the proof of concept that ion pairs were viable for controlling regioselectivity using transition metal catalysis; both delivered high levels of meta-selectivity in $\mathrm{C}-\mathrm{H}$ borylation. ${ }^{12-14} \mathrm{We}$ anticipated that the use of more conformationally flexible, less rigid substrates that possess greater degrees of freedom would be significantly more challenging when combined with the relatively low directionality of ion pairing and would provide a true test of the generality of the approach (Figure 1e).

Herein we demonstrate that, despite these challenges, ionpair-directed borylation proves to be highly effective, giving good to excellent levels of meta-selectivity on two flexible substrate classes: quaternized phenethylamines and phenylpropylamines. Furthermore, we have designed competition substrates that directly compare ion-pairing and hydrogen

Received: January 31, 2018

Revised: $\quad$ March 24, 2018

Published: March 26, 2018 
(a) Breslow, 1981:

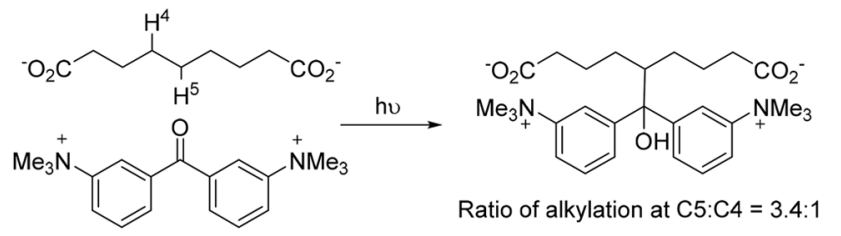

(b) Breslow, 1983:

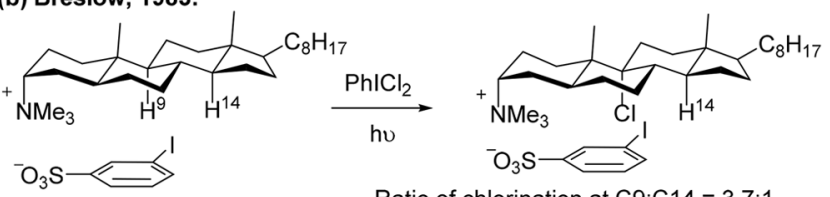

Ratio of chlorination at $\mathrm{C} 9: \mathrm{C} 14=3.7: 1$

(c) Ion pair-directed C-H borylation:
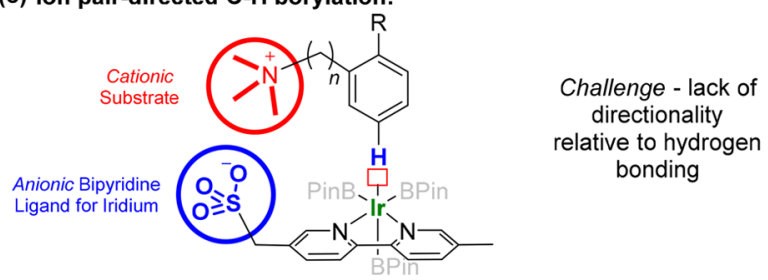

(d) Our previous work $(n=0,1)$ :

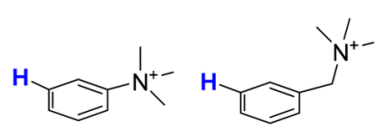

Rigid substrates with low conformational freedom

High meta-selectivity (e) This work $(n=2,3)$ :

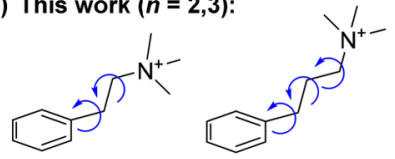

Flexible substrates with higher conformational freedom

Ion pair-directed $\mathrm{C}-\mathrm{H}$ activation still viable?
Figure 1. Previous examples of use of ion-pairing to control siteselective reactions and our previous and current work on directed C$\mathrm{H}$ borylation.

bonding in their directing ability for borylation. Our findings serve to highlight the potential of ion-pair-directed catalysis as a strategy for control of regioselectivity and site-selectivity in C$\mathrm{H}$ activation reactions.

At the outset of our studies, we focused on quaternary ammonium salts derived from phenethylamine derivatives. Numerous phenethylamines are readily available, and the biological importance of this class of molecules is very well established, with numerous pharmaceuticals possessing a phenethylamine motif embedded within their structure. We evaluated four anionic sulfonate ligands $(\mathbf{1 a - 1 d})$ alongside other borylation ligands dtbpy, bpy, and tmphen in the borylation of quaternized phenethylamine substrate 2a (Table $1) .{ }^{15} \mathrm{We}$ found that ligand $\mathbf{1 a}$, in which the sulfonate is connected to the bipyridine 5-position by a methylene spacer, was the optimal ligand giving 8.8:1 meta:para selectivity (entry 1). Strikingly, ligand 1a had also proved to be the optimal scaffold for not only our ion-pair directed borylation of aniline and benzylamine derived ammonium salts but also our recently reported hydrogen bond-directed borylation of benzylamines, phenethylamine, and phenylpropylamine-derived amides. ${ }^{7 f}$ Using dtbpy as ligand gave no reaction at all at $50{ }^{\circ} \mathrm{C}$ but good conversion at $70{ }^{\circ} \mathrm{C}$ (entries 5 and 6 ), while bpy gave only moderate conversion (entry 7). 3,4,7,8-Tetramethyl-1,10phenanthroline (tmphen) gave the highest yield and was subsequently used to assess intrinsic borylation regioselectivity (entry 8$){ }^{16}$

With ligand 1a identified as the optimal, we next evaluated the scope of the borylation on a range of quaternized phenethylamines that would be expected to undergo non-
Table 1. Evaluation of Anionic Ligands 1a-1d on Quaternized Phenethylamine 2a
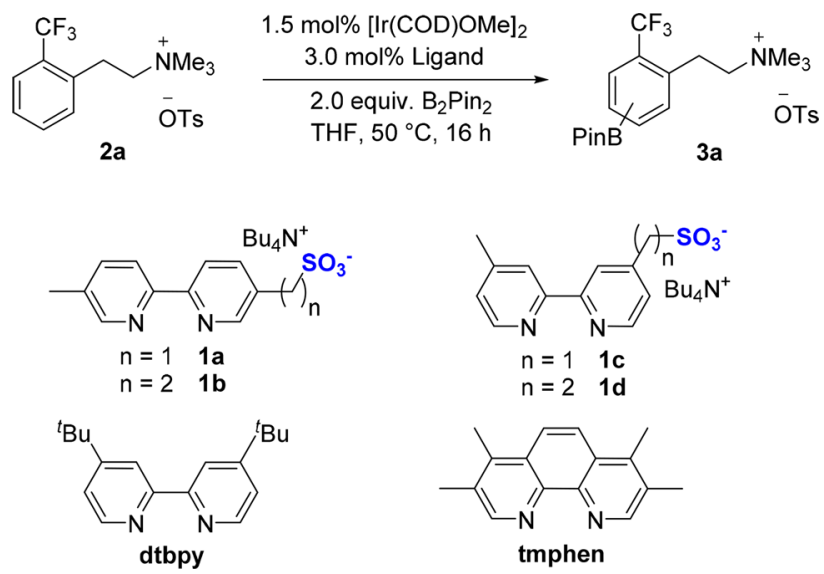

\begin{tabular}{cccc|} 
entry & ligand & meta:para $^{a}$ & ${\text { total yield }(\%)^{b}}^{b}$ \\
\hline 1 & 1a & $8.8: 1$ & 89 \\
2 & $\mathbf{1 b}$ & $5: 1$ & 89 \\
3 & $\mathbf{1 c}$ & $3.6: 1$ & 86 \\
4 & $\mathbf{1 d}$ & $1.7: 1$ & 98 \\
5 & dtbpy & -- & 0 \\
$6^{c}$ & dtbpy & $1: 2.0$ & 91 \\
$7^{c}$ & bpy & $1: 2.2$ & 51 \\
$8^{c}$ & tmphen & $1: 2.1$ & 96
\end{tabular}

${ }^{a}$ meta:para ratios are taken from analysis of crude ${ }^{1} \mathrm{H}$ NMR spectra. ${ }^{b}$ Yields determined by ${ }^{1} \mathrm{H}$ NMR with reference to 1,3,5-trimethoxybenzene internal standard. ${ }^{c}$ Reaction carried out at $70{ }^{\circ} \mathrm{C}$.

selective borylation using a standard borylation ligand (Table 2). A number of 2-substituted substrates proved to be compatible, including those substituted with halides (3b, 3c, and $\mathbf{3 d}$ ), an electron-withdrawing group (3a), and an aromatic substituent (3e). In the case of the 2-fluoro substrate $3 \mathbf{d}$, diborylation was found to be competitive with monoborylation, with high meta-selectivity. A pyridine-derived substrate gave excellent selectivity for borylation at the $\mathrm{C} 4$ position (3f). Furthermore, quaternary ammonium salts derived from substituted phenylalanines were also found to be compatible $(3 g-3 i)$. Interestingly, the ammonium salt derived from phenethylamine (i.e., with no substituents on the arene) was found to be unreactive using either ligand 1a or tmphen, even under forcing conditions. Similarly, electron-donating substituents on the aromatic ring, such as methyl and methoxy, also resulted in no reaction with either ligand. On the basis of these observations, we surmise that the presence of the ammonium functionality is, to some degree, reducing the reactivity of the active borylation catalyst. Therefore, correspondingly "activated" substrates, possessing electrondeficient substituents on the arene, are required. In our previous work with the zero and one-carbon chains, the strong inductive effect of the ammonium group close to the arene meant that most substrates were effectively electron deficient and so additional electron-donating groups were tolerated. However, in this present work, as the ammonium group moves further away from the arene, its inductive removal of electron density is significantly reduced. We also evaluated alternative counterions apart from tosylate to attempt to increase reactivity, but none was found to give significant improvement.

We next investigated the extension of the chain length by an additional methylene unit, introducing further flexibility into 
Table 2. Scope of Borylation of Substituted Quaternized Phenethylamines

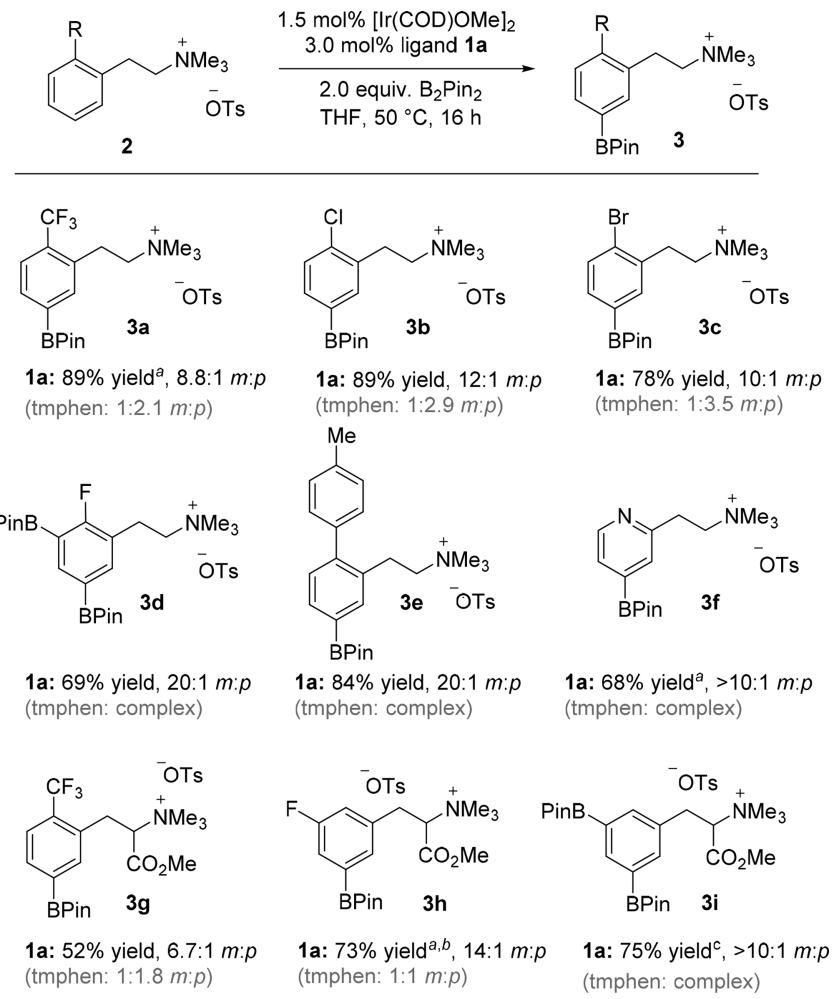

${ }^{a 1} \mathrm{H}$ NMR yield with reference to an internal standard quoted due to decomposition during purification. ${ }^{b}$ Reaction carried out at $70{ }^{\circ} \mathrm{C} .{ }^{c} 3.0$ equiv. of $\mathrm{B}_{2} \mathrm{Pin}_{2}$ employed.

the substrate. We evaluated all four sulfonate ligands $\mathbf{1 a}-\mathbf{1 d}$, dtbpy, and tmphen on quaternized phenylpropylamine substrate $4 \mathbf{a}$ (Table 3 ). These experiments demonstrated that

Table 3. Evaluation of Anionic Ligands 1a-1d on Quaternized Phenylpropylamine 4a

2.0 equiv. $\mathrm{B}_{2} \mathrm{Pin}_{2}$
$\mathrm{THF}, 50^{\circ} \mathrm{C}, 16 \mathrm{~h}$

${ }^{a}$ Reaction carried out at $70{ }^{\circ} \mathrm{C}$.

again ligand 1a was optimal, providing further indication of the broad generality of this ligand structure (entry 1 ). In this case, the meta-selectivity, at 5:1 was decreased when compared with the phenethylamine-derived salt. This is likely attributable to the greater flexibility of the substrate meaning that the entropic cost for an organized transition state is becoming increasingly high.

The scope of the borylation on a range of quaternized phenylpropylamine derivatives is shown in Table 4. As before, a number of substituents are compatible, including electronwithdrawing groups $(\mathbf{5 a}, \mathbf{5 e})$ and halides $(\mathbf{5 b}-\mathbf{d}, \mathbf{5 f})$.

Table 4. Scope of Borylation of Substituted, Quaternized Phenylpropylamines
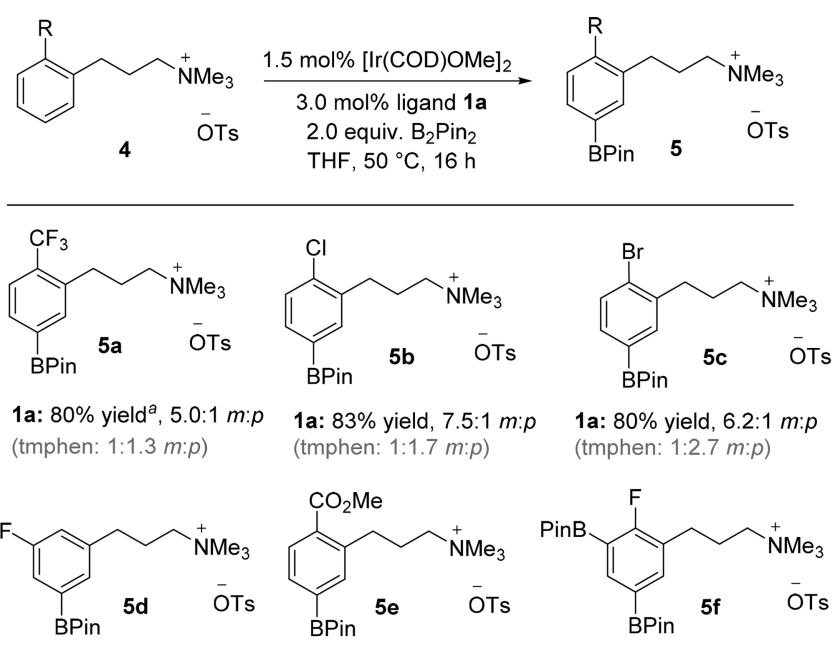

1a: $72 \%$ yield, 8.1:1 m:p $\quad$ 1a: $97 \%$ yield $^{a}, 18: 1 \mathrm{~m}: p \quad$ 1a: $75 \%$ yield $^{b}, 7.0: 1 \mathrm{~m}: \mathrm{p}$ (tmphen: $1: 1 \mathrm{~m}: \mathrm{p}$ ) (tmphen: $1.7: 1 \mathrm{~m}: \mathrm{p}$ ) (tmphen: $1.2: 1 \mathrm{~m}: \mathrm{p}$ )

${ }^{a 1} \mathrm{H}$ NMR yield with reference to an internal standard quoted due to decomposition during purification. ${ }^{b}$ Reaction carried out at $70^{\circ} \mathrm{C}$.

We also evaluated a substrate bearing a four-carbon linker, but we found that regioselectivity fell to below synthetically useful levels: 2-chloro-substituted $\mathbf{4 g}$ delivered a 4:1 $\mathrm{m:p}$ (Scheme 1). This is in comparison to $12: 1(\mathbf{3 b})$ and $7.5: 1(\mathbf{5 b})$

Scheme 1. Evaluation of a Substrate with a Four-Carbon Chain

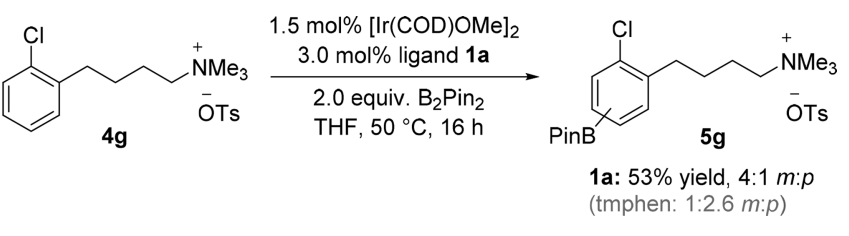

for the analogous two-carbon and three-carbon substrates bearing the 2-chloro substituent, showing that selectivity steadily decreases with increasing chain length and substrate flexibility.

Despite this, it is remarkable that a single ligand design proves to be optimal for four different chain lengths. We speculate that the sulfonate group of $1 \mathrm{a}$, with its negative charge delocalized across multiple atoms, serves as a diffuse area of high charge density at a fixed distance from the iridium center. Thus, as we postulated in our previous study on hydrogen bond-directed borylation, it seems reasonable that as long as a particular substrate is able to achieve a low-energy conformation that will allow an electrostatic interaction with the catalyst in the borylation transition state, then this may plausibly lead to meta-selective borylation. Ortho-borylation is disfavored on steric grounds and para-selective borylation would likely need a significantly extended ligand design. ${ }^{7 e}$ Ligand 1a, in which the methylenesulfonate group extends from the 5- and 5'-positions of the bipyridine, likely has a fairly restricted conformation, in which the $\mathrm{C}-\mathrm{S}$ bond is perpendicular to the plane of the bipyridine ring due to the 
bulk of the sulfonate group. This combination of proximity to the Ir center and low conformation flexibly could be key to the universal success of 1a (Figure 2). The longer chain length

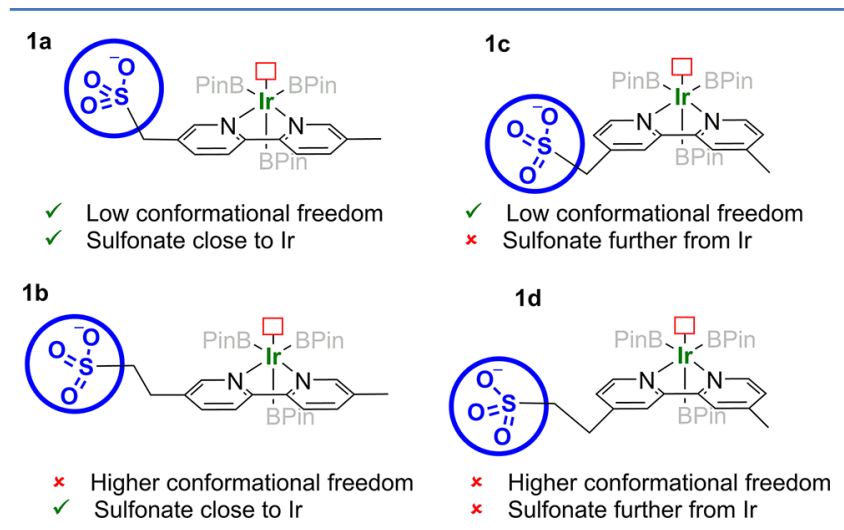

Figure 2. Possible rationalization of factors behind the broad generality of ligand 1a.

variant $\mathbf{1 b}$ typically gives the next best regioselectivity. This ligand still has proximity to Ir but with greater flexibility, resulting in a greater entropic cost compared with 1a. With ligands $1 \mathrm{c}$ and $1 \mathrm{~d}$, the sulfonate extends from the 4- and 4'positions and the resulting greater distance of the sulfonate from the Ir metal center appears less favorable. Although 1c and 1d ligands perform better on the longer chain substrates of the present study compared with the shorter chain variants of our previous study, as would be expected, they remain inferior to 1 a.

Aniline and benzylamine-derived quaternary ammonium salts are amenable to cross coupling at the ammonium functionality using either nickel or palladium catalysis. However, the longer chain lengths of the substrates in the present study mean that the ammonium functionality is no longer compatible with existing protocols, being too remote from the aromatic ring. ${ }^{17}$ We demonstrate a Suzuki-Miyaura cross-coupling/Hofmann elimination process which gives access to meta-aryl styrenes in good yield over two steps (Scheme 2a, 7). Hofmann elimination on these products after cross-coupling is facile, the amine starting materials are readily available, and the alkene functionality resulting from elimination is highly versatile. We also developed a protocol wherein amine functionality could be retained in the molecule, if desired. As demonstrated in Scheme

Scheme 2. Elaboration of Quaternary Ammonium Salt Products via (a) Suzuki-Miyaura Cross-Coupling/Hofmann Elimination and (b) Hydrogenation To Reveal Tertiary Amine

a)
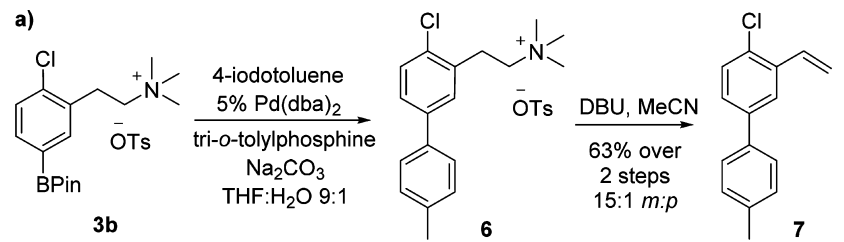

b)

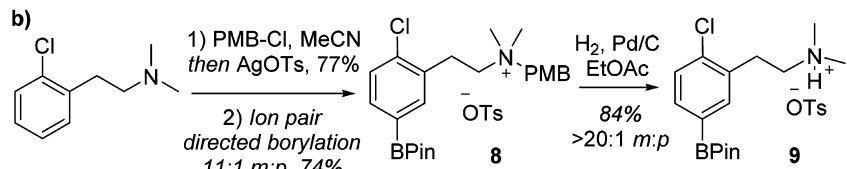

$2 \mathrm{~b}$, treatment of a tertiary amine with 4-methoxybenzyl chloride, followed by a counterion exchange gives a quaternary ammonium tosylate which undergoes the ion-pair-directed borylation giving 11:1 meta:para ratio in good yield (8). This product can then be simply hydrogenated to reveal the metaborylated tertiary amine $\mathbf{9}$ as its toluenesulfonic acid salt. Given the ubiquity of tertiary amine functionality in pharmaceuticals, we anticipate that this simple procedure of quaternization/ borylation/hydrogenation could be of significant practical utility in medicinal chemistry applications where flexible access to the meta position of an aromatic ring is required.

We recently demonstrated that the sulfonate group of ligand 1a functions very effectively as a hydrogen bond acceptor to allow the meta-selective borylation of amides derived from benzylamines, phenethylamines, and phenylpropylamines. ${ }^{7 f}$ This ability of a single ligand to engage highly effectively in both hydrogen bonding and ion-pairing interactions offers a rare and valuable opportunity to carry out a direct competition between these two most important classes of noncovalent interaction, in the context of a single molecule. Accordingly, we prepared 10, 11, and 12, which all feature a potential competition between ion-pair direction and hydrogen bond direction, with borylation regioselectivity indicating the outcome (Figure 3). These substrates demonstrated that, in all

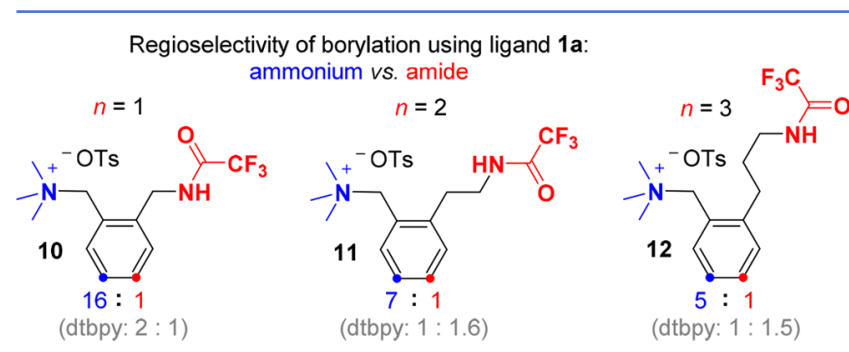

Figure 3. Substrates featuring an internal competition between ammonium and amide functionality.

cases, ion pair-directed borylation dominates to give highly selective borylation meta to the ammonium. The small but consistent decrease in the meta:para ratio (relative to the ammonium) from $\mathbf{1 0}$ through to $\mathbf{1 2}$ approximately corresponds to the trend we observed in the hydrogen bond-directed borylation, wherein higher meta selectivity was typically observed with the two and three carbon chains, compared with the one carbon chain. ${ }^{7 f}$

In summary, we have demonstrated that an ion pair-directed approach to controlling regioselectivity in iridium-catalyzed C$\mathrm{H}$ borylation is effective even on substrates that possess significant flexibility between the arene and the cationic group. This constitutes a powerful approach for introducing versatile boron functionality into the meta position of a range of aromatic amines. But more broadly, this work demonstrates the potential for wider application of the use of ion-pairing interactions to control regioselectivity and site-selectivity, challenging the assumption that lack of directionality should make ion pairs unsuitable as a controlling element in chemical reactions requiring high levels of precision. Additionally, while the utilization of catalyst-substrate hydrogen bonds is now a relatively commonly employed strategy, we have demonstrated here that in a direct competition, ion-pair direction appears to be the dominant director, at least in the context of $\mathrm{C}-\mathrm{H}$ borylation. We hope that these insights will provide an 
alternative outlook for those looking to exploit attractive noncovalent interactions to direct catalysis.

\section{ASSOCIATED CONTENT}

\section{S Supporting Information}

The Supporting Information is available free of charge on the ACS Publications website at DOI: 10.1021/acscatal.8b00423.

General information and procedures, detailed chemical procedures, references, and other supplemental data (PDF)

\section{AUTHOR INFORMATION}

\section{Corresponding Author}

*E-mail: rjp71@cam.ac.uk.

\section{ORCID $\odot$}

Robert J. Phipps: 0000-0002-7383-5469

\section{Notes}

The authors declare no competing financial interest.

\section{ACKNOWLEDGMENTS}

We are grateful to AstraZeneca for a studentship (M.T.M.) through the AZ-Cambridge $\mathrm{PhD}$ Program, the EPSRC and Pfizer for a CASE studentship (H.J.D.), the Royal Society for a University Research Fellowship (R.J.P.), the EPSRC (EP/ N005422/1, G.R.G.) and EPSRC UK National Mass Spectrometry Facility at Swansea University. We thank Professors Steven V. Ley and Matthew J. Gaunt for support and useful discussions, and Dr. Iain Cumming (AstraZeneca) and Dr. David Blakemore (Pfizer) for useful discussion.

\section{REFERENCES}

(1) (a) Dydio, P.; Reek, J. N. H. Supramolecular control of selectivity in transition-metal catalysis through substrate preorganization. Chem. Sci. 2014, 5, 2135-2145. (b) Raynal, M.; Ballester, P.; Vidal-Ferran, A.; van Leeuwen, P. W. N. M. Supramolecular catalysis. Part 1: noncovalent interactions as a tool for building and modifying homogeneous catalysts. Chem. Soc. Rev. 2014, 43, 1660-1733.

(2) Gröger, H.; Asano, Y. In Enzyme Catalysis in Organic Synthesis; Wiley-VCH Verlag GmbH \& Co. KGaA: Weinheim, 2012; pp 1-42.

(3) For selected reviews on asymmetric transition-metal catalysis incorporating hydrogen bonding elements, see: (a) Zhao, B.; Han, Z.; Ding, K. The N-H Functional Group in Organometallic Catalysis. Angew. Chem., Int. Ed. 2013, 52, 4744-4788. (b) Sawamura, M.; Ito, Y. Catalytic asymmetric synthesis by means of secondary interaction between chiral ligands and substrates. Chem. Rev. 1992, 92, 857-871. (c) Breit, B. Supramolecular Approaches to Generate Libraries of Chelating Bidentate Ligands for Homogeneous Catalysis. Angew. Chem., Int. Ed. 2005, 44, 6816-6825.

(4) (a) Phipps, R. J.; Hamilton, G. L.; Toste, F. D. The progression of chiral anions from concepts to applications in asymmetric catalysis. Nat. Chem. 2012, 4, 603-614. (b) Brak, K.; Jacobsen, E. N. Asymmetric Ion-Pairing Catalysis. Angew. Chem., Int. Ed. 2013, 52, 534-561. (c) Mahlau, M.; List, B. Asymmetric Counteranion-Directed Catalysis: Concept, Definition, and Applications. Angew. Chem., Int. Ed. 2013, 52, 518-533. (d) Ohmatsu, K.; Ito, M.; Kunieda, T.; Ooi, T. Ion-paired chiral ligands for asymmetric palladium catalysis. Nat. Chem. 2012, 4, 473-477. (e) Hamilton, G. L.; Kang, E. J.; Mba, M.; Toste, F. D. A Powerful Chiral Counterion Strategy for Asymmetric Transition Metal Catalysis. Science 2007, 317, 496-499. (f) Mukherjee, S.; List, B. Chiral Counteranions in Asymmetric Transition-Metal Catalysis: Highly Enantioselective Pd/Brønsted Acid-Catalyzed Direct $\alpha$-Allylation of Aldehydes. J. Am. Chem. Soc. 2007, 129, 11336-11337.
(5) Davis, H. J.; Phipps, R. J. Harnessing non-covalent interactions to exert control over regioselectivity and site-selectivity in catalytic reactions. Chem. Sci. 2017, 8, 864-877.

(6) For selected examples of use of hydrogen bonds to control regioselectivity or site-selectivity in transition-metal catalysis, see: (a) Breslow, R.; Zhang, X.; Huang, Y. Selective Catalytic Hydroxylation of a Steroid by an Artificial Cytochrome P-450 Enzyme. J. Am. Chem. Soc. 1997, 119, 4535-4536. (b) Das, S.; Incarvito, C. D.; Crabtree, R. H.; Brudvig, G. W. Molecular Recognition in the Selective Oxygenation of Saturated C-H Bonds by a Dimanganese Catalyst. Science 2006, 312, 1941-1943. (c) Grünanger, C. U.; Breit, B. Branched-Regioselective Hydroformylation with Catalytic Amounts of a Reversibly Bound Directing Group. Angew. Chem., Int. Ed. 2008, 47, 7346-7349. (d) Fackler, P.; Berthold, C.; Voss, F.; Bach, T. Hydrogen-Bond-Mediated Enantioand Regioselectivity in a Ru-Catalyzed Epoxidation Reaction. J. Am. Chem. Soc. 2010, 132, 15911-15913. (e) Dydio, P.; Detz, R. J.; Reek, J. N. H. Precise Supramolecular Control of Selectivity in the RhCatalyzed Hydroformylation of Terminal and Internal Alkenes. J. Am. Chem. Soc. 2013, 135, 10817-10828.

(7) For examples of use of noncovalent interactions to control regioselectivity in $\mathrm{C}-\mathrm{H}$ borylation, see: (a) Roosen, P. C.; Kallepalli, V. A.; Chattopadhyay, B.; Singleton, D. A.; Maleczka, R. E.; Smith, M. R. Outer-Sphere Direction in Iridium C-H Borylation. J. Am. Chem. Soc. 2012, 134, 11350-11353. (b) Preshlock, S. M.; Plattner, D. L.; Maligres, P. E.; Krska, S. W.; Maleczka, R. E.; Smith, M. R. A Traceless Directing Group for C-H Borylation. Angew. Chem., Int. Ed. 2013, 52, 12915-12919. (c) Kuninobu, Y.; Ida, H.; Nishi, M.; Kanai, M. A metaselective $\mathrm{C}-\mathrm{H}$ borylation directed by a secondary interaction between ligand and substrate. Nat. Chem. 2015, 7, 712-717. (d) Chattopadhyay, B.; Dannatt, J. E.; Andujar-De Sanctis, I. L.; Gore, K. A.; Maleczka, R. E.; Singleton, D. A.; Smith, M. R. Ir-Catalyzed orthoBorylation of Phenols Directed by Substrate-Ligand Electrostatic Interactions: A Combined Experimental/in Silico Strategy for Optimizing Weak Interactions. J. Am. Chem. Soc. 2017, 139, 78647871. (e) Hoque, M. E.; Bisht, R.; Haldar, C.; Chattopadhyay, B. Noncovalent Interactions in Ir-Catalyzed $\mathrm{C}-\mathrm{H}$ Activation: L-Shaped Ligand for Para-Selective Borylation of Aromatic Esters. J. Am. Chem. Soc. 2017, 139, 7745-7748. (f) Davis, H. J.; Genov, G. R; Phipps, R. J. meta-Selective $\mathrm{C}-\mathrm{H}$ Borylation of Benzylamine-, Phenethylamine-, and Phenylpropylamine-Derived Amides Enabled by a Single Anionic Ligand. Angew. Chem., Int. Ed. 2017, 56, 13351-13355.

(8) Breslow, R. In Artificial Enzymes; Wiley-VCH Verlag GmbH \& Co. KGaA: Weinheim, 2006; pp 1-35.

(9) Breslow, R.; Rajagopalan, R.; Schwarz, J. Selective functionalization of doubly coordinated flexible chains. J. Am. Chem. Soc. 1981, 103, 2905-2907.

(10) Breslow, R.; Heyer, D. Directed steroid chlorination catalyzed by an ion-paired template. Tetrahedron Lett. 1983, 24, 5039-5042.

(11) Davis, H. J.; Mihai, M. T.; Phipps, R. J. Ion Pair-Directed Regiocontrol in Transition-Metal Catalysis: A Meta-Selective $\mathrm{C}-\mathrm{H}$ Borylation of Aromatic Quaternary Ammonium Salts. J. Am. Chem. Soc. 2016, 138, 12759-12762.

(12) For examples of directed, meta-selective $\mathrm{C}-\mathrm{H}$ borylation reactions, see refs 7c,f and Bisht, R.; Chattopadhyay, B. Formal IrCatalyzed Ligand-Enabled Ortho and Meta Borylation of Aromatic Aldehydes via in Situ-Generated Imines. J. Am. Chem. Soc. 2016, 138, 84-87.

(13) For reviews on meta-selective $\mathrm{C}-\mathrm{H}$ functionalization using transition-metal catalysis, see: (a) Dey, A.; Agasti, S.; Maiti, D. Palladium catalysed meta-C-H functionalization reactions. Org. Biomol. Chem. 2016, 14, 5440-5453. (b) Mihai, M. T.; Genov, G. R.; Phipps, R. J. Access to the meta position of arenes through transition metal catalysed $\mathrm{C}-\mathrm{H}$ bond functionalisation: a focus on metals other than palladium. Chem. Soc. Rev. 2018, 47, 149-171.

(14) For selected references on meta-selective $\mathrm{C}-\mathrm{H}$ functionalization using transition-metal catalysis, see: (a) Zhang, Y.-H.; Shi, B.-F.; Yu, J.Q. Pd(II)-Catalyzed Olefination of Electron-Deficient Arenes Using 2,6-Dialkylpyridine Ligands. J. Am. Chem. Soc. 2009, 131, 5072-5074. 
(b) Phipps, R. J.; Gaunt, M. J. A Meta-Selective Copper-Catalyzed CH Bond Arylation. Science 2009, 323, 1593-1597. (c) Saidi, O.; Marafie, J.; Ledger, A. E. W.; Liu, P. M.; Mahon, M. F.; Kociok-Köhn, G.; Whittlesey, M. K.; Frost, C. G. Ruthenium-Catalyzed Meta Sulfonation of 2-Phenylpyridines. J. Am. Chem. Soc. 2011, 133, 1929819301. (d) Leow, D.; Li, G.; Mei, T.-S.; Yu, J.-Q. Activation of remote meta-C-H bonds assisted by an end-on template. Nature 2012, 486, 518-522. (e) Hofmann, N.; Ackermann, L. meta-Selective C-H Bond Alkylation with Secondary Alkyl Halides. J. Am. Chem. Soc. 2013, 135, 5877-5884. (f) Bera, M.; Modak, A.; Patra, T.; Maji, A.; Maiti, D. Meta-Selective Arene $\mathrm{C}-\mathrm{H}$ Bond Olefination of Arylacetic Acid Using a Nitrile-Based Directing Group. Org. Lett. 2014, 16, 5760-5763. (g) Tang, R.-Y.; Li, G.; Yu, J.-Q. Conformation-induced remote metaC-H activation of amines. Nature 2014, 507, 215-220. (h) Dong, Z.; Wang, J.; Dong, G. Simple Amine-Directed Meta-Selective C-H Arylation via Pd/Norbornene Catalysis. J. Am. Chem. Soc. 2015, 137, 5887-5890. (i) Wang, X.-C.; Gong, W.; Fang, L.-Z.; Zhu, R.-Y.; Li, S.; Engle, K. M.; Yu, J.-Q. Ligand-enabled meta-C-H activation using a transient mediator. Nature 2015, 519, 334-338. (j) Fan, Z.; Ni, J.; Zhang, A. Meta-Selective CAr-H Nitration of Arenes through a Ru3(CO)12-Catalyzed Ortho-Metalation Strategy. J. Am. Chem. Soc. 2016, 138, 8470-8475. (k) Bera, M.; Agasti, S.; Chowdhury, R.; Mondal, R.; Pal, D.; Maiti, D. Rhodium-Catalyzed meta-C-H Functionalization of Arenes. Angew. Chem., Int. Ed. 2017, 56, 5272. (1) Xu, H.-J.; Lu, Y.; Farmer, M. E.; Wang, H.-W.; Zhao, D.; Kang, Y.S.; Sun, W.-Y.; Yu, J.-Q. Rh(III)-Catalyzed meta-C-H Olefination Directed by a Nitrile Template. J. Am. Chem. Soc. 2017, 139, 22002203. (m) Ding, Q.; Ye, S.; Cheng, G.; Wang, P.; Farmer, M. E.; Yu, J.Q. Ligand-Enabled meta-Selective C-H Arylation of Nosyl-Protected Phenethylamines, Benzylamines, and 2-Aryl Anilines. J. Am. Chem. Soc. 2017, 139, 417-425.

(15) For reviews and key references relating to Ir-catalyzed $\mathrm{C}-\mathrm{H}$ borylation, see: (a) Mkhalid, I. A. I.; Barnard, J. H.; Marder, T. B.; Murphy, J. M.; Hartwig, J. F. C-H Activation for the Construction of C-B Bonds. Chem. Rev. 2010, 110, 890-931. (b) Ros, A.; Fernandez, R.; Lassaletta, J. M. Functional group directed C-H borylation. Chem. Soc. Rev. 2014, 43, 3229-3243. (c) Cho, J.-Y.; Tse, M. K.; Holmes, D.; Maleczka, R. E.; Smith, M. R. Remarkably Selective Iridium Catalysts for the Elaboration of Aromatic C-H Bonds. Science 2002, 295, 305308. (d) Ishiyama, T.; Takagi, J.; Ishida, K.; Miyaura, N.; Anastasi, N. R.; Hartwig, J. F. Mild Iridium-Catalyzed Borylation of Arenes. High Turnover Numbers, Room Temperature Reactions, and Isolation of a Potential Intermediate. J. Am. Chem. Soc. 2002, 124, 390-391. (e) Boller, T. M.; Murphy, J. M.; Hapke, M.; Ishiyama, T.; Miyaura, N.; Hartwig, J. F. Mechanism of the Mild Functionalization of Arenes by Diboron Reagents Catalyzed by Iridium Complexes. Intermediacy and Chemistry of Bipyridine-Ligated Iridium Trisboryl Complexes. J. Am. Chem. Soc. 2005, 127, 14263-14278. (f) Xu, L.; Wang, G.; Zhang, S.; Wang, H.; Wang, L.; Liu, L.; Jiao, J.; Li, P. Recent advances in catalytic $\mathrm{C}-\mathrm{H}$ borylation reactions. Tetrahedron 2017, 73, 7123-7157. (g) Haldar, C.; Emdadul Hoque, M.; Bisht, R.; Chattopadhyay, B. Concept of Ir-catalyzed $\mathrm{CH}$ bond activation/borylation by noncovalent interaction. Tetrahedron Lett. 2018, 59, 1269-1277.

(16) (a) Liskey, C. W.; Hartwig, J. F. Iridium-Catalyzed Borylation of Secondary C-H Bonds in Cyclic Ethers. J. Am. Chem. Soc. 2012, 134, 12422-12425. (b) Preshlock, S. M.; Ghaffari, B.; Maligres, P. E.; Krska, S. W.; Maleczka, R. E.; Smith, M. R. High-Throughput Optimization of Ir-Catalyzed C-H Borylation: A Tutorial for Practical Applications. J. Am. Chem. Soc. 2013, 135, 7572-7582.

(17) A recent report from Watson and co-workers disclosed the Nickel-catalyzed Suzuki-Miyaura coupling of phenethylamine-derived pyridinium salts Basch, C. H.; Liao, J.; Xu, J.; Piane, J. J.; Watson, M. P. Harnessing Alkyl Amines as Electrophiles for Nickel-Catalyzed Cross Couplings via C-N Bond Activation. J. Am. Chem. Soc. 2017, 139, 5313 We tested our directed borylation on a pyridinium salt similar to those used in their study but unfortunately observed no reactivity in the borylation. 